\title{
ASSESS THE PREVALENCE OF RESPIRATORY PROBLEM AND KNOWLEDGE ON HEALTH EFFECTS OF PEOPLE RESIDING NEAR QUARRY
}

\author{
SAHBANATHUL MISSRIYA M. A. ${ }^{1 *}$, SUBASHINI S. ${ }^{2}$ \\ ${ }^{1}$ Saveetha College of Nursing, Saveetha University, Chennai, India, ${ }^{2}$ Bsc (N), Saveetha College of Nursing, Saveetha University, Chennai, \\ India \\ Email: contschn002@gmail.com
}

Received: 08 Nov 2016 Revised and Accepted: 21 Dec 2016

\begin{abstract}
Objective: In the quarry area, there are various suspended particulate matters are mixed with the ambient air in and around. People residing near to that quarry areas are exposed to hazards through the inhalation of airborne particulates. Due to that, the respiratory problems are very common among them. The study was aimed to assess the prevalence of respiratory problems and determine the level of knowledge on health effects of people living near to quarry at Kundrathur.
\end{abstract}

Methods: Descriptive cross-sectional research design was adopted. Convenient sampling technique was used to select 60 people residing near the quarry. The data was collected by using structured questionnaire through face to face interview. The collected data was organised and analysed by descriptive and inferential statistics.

Results: The study findings showed that the prevalence of respiratory problems was high $41(68.33 \%)$ among people residing near the quarry and $19(31.66 \%)$ people did not show any signs and symptoms of respiratory problems. The knowledge regarding health effects was showing that $39(65 \%)$ people had inadequate knowledge, 21(35\%) people had the moderate knowledge, and none of the people had adequate knowledge.

Conclusion: The study concluded that, though there was the prevalence of respiratory problems and most of them had inadequate knowledge on health effects and there is a need to advise the people about safety from respiratory diseases.

Keywords: Assess, Prevalence, Respiratory Problem, Health effects

(C) 2017 The Authors. Published by Innovare Academic Sciences Pvt Ltd. This is an open access article under the CC BY license (http://creativecommons.org/licenses/by/4. 0/) DOI: http://dx.doi.org/10.22159/ijpps.2017v9i2.16214

\section{INTRODUCTION}

Dust generated from crushing of granite rocks is hazardous to the human health. Because inhalation of the dust damages lung function and causes some respiratory and non-respiratory symptoms. The quarry workers are used to affect with these illnesses [1]. Respiratory diseases are defined as chronic diseases of the respiratory tract, and other structures of the lung amongst the most common diseases are asthma and chronic obstructive pulmonary disease. These diseases represent a challenge to the public health in both industrialised and developing countries because of their frequency and economic impact [2].

In 1990, the World Health Organization/World Bank Global Burden of Disease study estimated the global prevalence of Chronic Obstructive Pulmonary Disease (COPD) to be 9.33 per 1000 individuals for men and 7.33 per 1000 for women [3]. The prevalence was observed to be higher in industrialised countries [1].

The quarrying is an economic activity in areas endowed with natural resources such as marble, limestone and gypsum. Workers, as well as people residing nearby places in the quarry industries, are exposed to various hazards due to the inhalation of airborne particulates, and these causes many problems to their health. This leads to potential health risk to people of the quarry in the form of respiratory, dermal, ocular irritation and damage [4].

It is widely known that particulate matter pollutes the air and it is also associated with a variety of adverse health effects in humans [5]. These particulates can originate from stationary, mobile, or natural sources and its effects on human health vary depending on its size [6]. Particulate matter $<2.5 \mu \mathrm{m}$ in diameter (fine particulates; PM2.5) and $10 \mu \mathrm{m}$ (coarse particulate; PM10) are strongly associated with respiratory diseases and other adverse health effects in humans which include hypertension and cardiovascular conditions, allergies and inflammatory reactions, birth defects and deficiencies in child development [7].
The elderly people and people with emphysema, asthma, other respiratory diseases and chronic heart and lung diseases are especially sensitive to fine-particle pollution [8]

In Chennai, Stone quarries are more in Pallavaram and Kundrathur. Indian study on the epidemiology of asthma, respiratory symptoms, and chronic bronchitis reported that in 2006-2009, the respiratory illnesses and bronchitis were more common among people living at Kundrathur [9].

Hence the researcher felt that there is a need to study to assess the prevalence of respiratory problem and knowledge on health effects among people residing near the quarry. The study was aimed to assess the prevalence of respiratory problems and determine the level of knowledge on health effects of people living near to quarry at Kundrathur.

\section{MATERIALS AND METHODS}

\section{Research design}

In observational research, Descriptive cross-sectional design was chosen to assess the prevalence of respiratory problem and knowledge on health effects of people residing near the quarry. The study was conducted in Kundrathur area. Sikkarayapuram. These places are panchayat town in Kundrathur placed at Chennai. This place is famous for quarries and crushers. It is located very close to the residential area where more than 50000 people are living.

\section{Sampling method}

The sample size for this study was 60 people residing near the quarry at Kundrathur area. Convenient sampling technique was used for the study. The inclusion criteria were people aged more 20 $\mathrm{y}$ of both sexes with a willingness to participate in the study and able to understand Tamil or English languages. The information sheet was provided to the samples, and informed consent was obtained. 
Chronic and critically ill people were excluded from the study. Prior permission was obtained from the Institutional Review Board and approval from the Institutional Human Ethical Clearance Board of Saveetha University (SU/0743/2016).

\section{Tool}

The tool used in the study included part. 1 consists of demographic variables of age, sex, religion, education, place of living, social habits, occupation, duration of working experience, monthly income and family history of respiratory problems.

Part.2 included a checklist to find out the common respiratory illness among the quarry people to assess the prevalence of respiratory problem by structured interview method.

Part.3 consisted of a questionnaire to assess the knowledge regarding health effect structured interview method. The score interpretation for assessing knowledge was $<50 \%$-inadequate knowledge, $50 \%-75 \%$-moderate knowledge and $>75 \%$-adequate knowledge.

The purpose of the study was explained to the people, and their consent was obtained after providing information sheet. The main study was conducted in June-July 2016. The descriptive and inferential statistics were used for data analysis.

\section{RESULTS}

The collected data was analysed and tabulated for the purpose of interpreting the results.

The study findings showed that the prevalence of respiratory problems was high. Among the 60 people residing near quarry $41(68.33 \%)$ were having respiratory problems and $19(31.66 \%)$ people did not show any signs and symptoms of respiratory problems.

\section{Demographic variables of people residing near quarry}

The frequency and percentage distribution of socio-demographic variables of people residing near quarry was shown in table 1 .

Out of 60 people $17(28.3 \%)$ of the participants were in the age of a group of 20-30 y, 15(25\%) were in the age group of 31-40 y, 11(18.3\%) were in age group of above $50 \mathrm{y}$. regarding gender $37(62 \%)$ of the samples were males, 23(38.3\%) of the samples were females.

Regarding religion, majority 54(90\%) were Hindus. Regarding education in the study group, $21(35 \%)$ were illiterate, $22(36.6 \%)$ were studied till primary education and $7(11.6 \%)$ were graduated Regarding the place of living, 17(28.3\%) people were in working site.

Regarding social habits $16(26.6 \%)$ were smokers, 9(15\%) were alcoholic. Regarding occupation, 9(15\%) were quarry workers, 25 $(41.6 \%)$ were coolie, $12(20 \%)$ were business and $14(23.3 \%)$ were belongs to others.

Regarding working experience, $10(16.6 \%)$ of people were having 1-5 y of experience. Regarding income, 14 (6.6\%) were having<Rs.5000 as their income, 17 (28.3\%) were having 5000-10000, 36 (60\%) were having 10000-15000, 3(5\%) were having more than 15000 .

About the occurrence of respiratory problem $36(60 \%)$ were getting respiratory problems as an acute condition and remaining $24(40 \%)$ were having as a chronic problem.

\section{Knowledge level regarding the health effects}

The frequency and percentage distribution of knowledge level of regarding the health effects of people residing near quarry were shown in fig. 1.

Out of 60 people 39(65\%) had inadequate knowledge, 21(35\%) had moderately adequate knowledge, and none had adequate knowledge. The mean and standard deviation of the study were 7 and 2.76 .

Table 1: Frequency and percentage distribution of demographic variables of people residing near quarry $(n=60)$

\begin{tabular}{|c|c|c|c|c|c|}
\hline S. No. & Demographic variables & & & Frequency & Percentage \\
\hline \multirow[t]{4}{*}{1.} & Age & a. & $20-30$ & 17 & $28.3 \%$ \\
\hline & & b. & $31-40$ & 15 & $25 \%$ \\
\hline & & c. & $41-50$ & 17 & $28.3 \%$ \\
\hline & & $\mathrm{d}$. & Above 50 & 11 & $18.3 \%$ \\
\hline \multirow[t]{2}{*}{2.} & Sex & a. & Male & 37 & $62 \%$ \\
\hline & & b. & Female & 23 & $38.3 \%$ \\
\hline \multirow[t]{3}{*}{3.} & Religion & a. & Hindu & 54 & $90 \%$ \\
\hline & & b. & Muslim & 0 & 0 \\
\hline & & c. & Christian & 6 & $10 \%$ \\
\hline \multirow[t]{4}{*}{4.} & Education & a. & Illiterate & 21 & $35 \%$ \\
\hline & & b. & Primary & 22 & $36.6 \%$ \\
\hline & & c. & Higher Secondary & 10 & $16.6 \%$ \\
\hline & & $\mathrm{d}$. & Graduates & 7 & $11.6 \%$ \\
\hline \multirow[t]{4}{*}{5.} & Place of living & a. & On the working site & 17 & $28.3 \%$ \\
\hline & & b. & Out to working site & 22 & $36.6 \%$ \\
\hline & & c. & One $\mathrm{Km}$ radius & 2 & $3.3 \%$ \\
\hline & & d. & $>1 \mathrm{Km}$ radius & 19 & $31.6 \%$ \\
\hline \multirow[t]{3}{*}{6.} & Bad habits & a. & Smoker & 16 & $26.6 \%$ \\
\hline & & b. & Alcoholic & 9 & $15 \%$ \\
\hline & & c. & None of these & 35 & $58.3 \%$ \\
\hline \multirow[t]{4}{*}{7.} & Occupation & a. & Quarry worker & 9 & $15 \%$ \\
\hline & & b. & Coolie & 25 & $41.6 \%$ \\
\hline & & c. & Business & 12 & $20 \%$ \\
\hline & & d. & others & 14 & $23.3 \%$ \\
\hline \multirow[t]{4}{*}{8.} & Duration of working experience & a. & $1-5 y$ & 10 & $16.6 \%$ \\
\hline & & b. & $6-10 y$ & 15 & $25 \%$ \\
\hline & & c. & $11-15 y$ & 21 & $35 \%$ \\
\hline & & $\mathrm{d}$. & More than $20 \mathrm{y}$ & 14 & $23.3 \%$ \\
\hline \multirow[t]{4}{*}{9.} & Monthly Income & a. & $<$ Rs.5000 & 4 & $6.6 \%$ \\
\hline & & b. & Rs.5000-10000 & 17 & $28.3 \%$ \\
\hline & & c. & Rs. $10000-15000$ & 36 & $60 \%$ \\
\hline & & d. & $>$ Rs. 15000 & 3 & $5 \%$ \\
\hline \multirow[t]{2}{*}{10.} & Occurrence of respiratory problem & a. & Acute & 36 & $60 \%$ \\
\hline & & b. & Chronic & 24 & $40 \%$ \\
\hline
\end{tabular}

F-Frequency; \%-Percentage; $n=60$ 


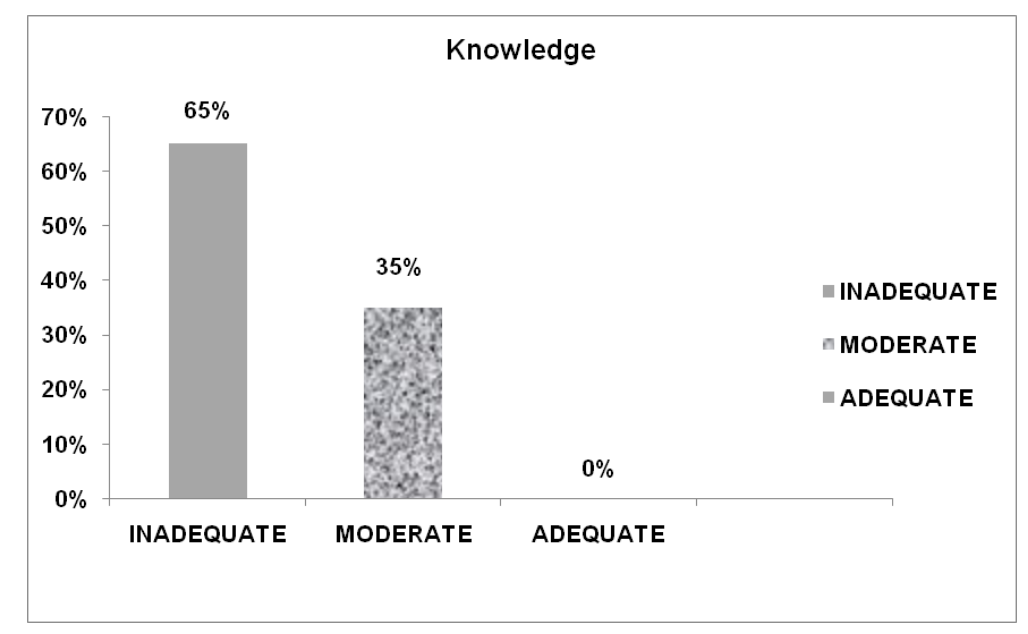

Fig. 1

Association between the knowledge of health effects with the selected demographic variables

The association between the knowledge of health effects with the selected demographic variables of people residing near quarry was shown in table 2 . The association between the knowledge of health effects with the selected demographic variables by using chi-square, showing that there was a significant association between the knowledge regarding the health effects with sex, education, place of living, occupation, duration of working experience of the people among the demographic variables. There was a non-significant association between the knowledge regarding the health effects and age, religion, bad habits, income, occurrence of respiratory problems among the demographic variables.

Table 2: Association of the knowledge regarding the health effect with selected demographic variables of people residing near quarry (n=600

\begin{tabular}{|c|c|c|c|c|c|c|}
\hline \multirow[t]{2}{*}{ S. No. } & \multirow[t]{2}{*}{ Demographic variables } & \multicolumn{2}{|c|}{ Inadequate } & \multicolumn{2}{|c|}{ Moderate } & \multirow[t]{2}{*}{ Chi-Square } \\
\hline & & $\mathrm{N}$ & $\%$ & $\mathrm{~N}$ & $\%$ & \\
\hline \multirow[t]{3}{*}{1.} & Sex & & & & & $x^{2}=1075$ \\
\hline & a. Male & 24 & 40 & 13 & 21.66 & $\begin{array}{l}x=10.75 \\
d f-2\end{array}$ \\
\hline & b. Female & 15 & 60 & 8 & 12.13 & $\begin{array}{l}\mathrm{dt}=2, \mathrm{p}=5.99 \\
(\mathrm{~S})\end{array}$ \\
\hline \multirow[t]{5}{*}{2.} & Education & & & & & $\gamma^{2}-1821$ \\
\hline & a. Illiterate & 15 & 25 & 6 & 10 & $\Lambda=18.31$ \\
\hline & b. Primary & 16 & 26.66 & 6 & 9.99 & $\mathrm{df}=6$, \\
\hline & c. High School & 5 & 8.33 & 5 & 8.33 & $\mathrm{p}=12.59$ \\
\hline & d. Degree and others & 3 & 5 & 4 & 6.66 & (S) \\
\hline \multirow[t]{5}{*}{3.} & Place of living & & & & & $\chi^{2}=18.23$ \\
\hline & a. On the working site & 12 & 25 & 6 & 10 & $\mathrm{df}=6$ \\
\hline & b. Out of working site & 11 & 26.66 & 6 & 7.99 & $\mathrm{p}=12.59$ \\
\hline & c. $1 \mathrm{Km}$ radius & 2 & 8.33 & 5 & 8.33 & $(S)$ \\
\hline & d. $>1 \mathrm{Km}$ radius & 14 & 5 & 4 & 6.66 & \\
\hline \multirow[t]{5}{*}{4.} & Occupation & & & & & $\chi^{2}=22.57$ \\
\hline & a. Quarry workers & 6 & 10 & 3 & 5 & $\mathrm{df}=6$ \\
\hline & b. Coolie & 18 & 30 & 7 & 11.66 & $p=12.59$ \\
\hline & c. Business & 8 & 13.33 & 4 & 6.66 & $\begin{array}{l}p-12.59 . \\
(S)\end{array}$ \\
\hline & d. Others & 7 & 11.66 & 7 & 11 & \\
\hline \multirow[t]{5}{*}{5.} & Duration of working experience & & & & & $\gamma^{2}$ \\
\hline & a. $1-5 y$ & 7 & 11.66 & 4 & 6.66 & $\chi=22.92$, \\
\hline & b. $5-10 y$ & 10 & 16.66 & 5 & 8.13 & $\mathrm{df}=6$, \\
\hline & c. $10-15 y$ & 14 & 23.33 & 7 & 11.66 & $\mathrm{p}=12.59$ \\
\hline & d.>15years & 8 & 13.33 & 5 & 8.13 & $(\mathrm{~S})$ \\
\hline
\end{tabular}

-Chi-square S-Significant

\section{DISCUSSION}

The first objective of the study was to assess the prevalence on the respiratory problem in people residing near the quarry. The present study was conducted in Kundrathur near Sikkarayapuram among people residing near the quarry. From the above table the data analysis showed that out off 60 people, 41(68.33\%) people showed evidence of the respiratory problem and 19(31.66\%) are not having any sign and symptoms of the respiratory problem.

A similar result was documented shows that the prevalence of respiratory symptoms was remarkably higher among quarry workers who work in the sites compared to their counterparts working in the offices. It is concluded that the site workers are exposed to higher levels of quarry dust. The limited and non-use of personal protected equipment (PPE) by quarry workers leads to the high prevalence of respiratory symptoms. Nwibo et al. reported a higher prevalence of $47.6 \%$ for a cough and $40.7 \%$ for chest pain among quarry workers in Ebonyi state, southeastern Nigeria [10].

Another study on effects of quarry activities on some selected communities in the lower Manya Krobo District of the Eastern Region of Ghana conducted by Vincent Kodzo Nartey, Joseph Nii Nanor and Raphael Kweku Klake. The study resulted that the 
prevalence of malaria was high but it was not related to dust emissions, it resulted from mosquitoes breeding in the stagnant pools of water found in pits created as a result of the mining activity. The common health problems were acute respiratory tract infection, ear and eye infections, cough and pneumonia [11]

In this current study the distribution of knowledge on regarding health effects in people residing near quarry revealed that $39(65 \%)$ had inadequate knowledge, $21(35 \%)$ had the moderate knowledge and none of them had adequate knowledge. The mean and standard deviation of the study were as follows 7 and 2.76 .

Air pollution causes many major health issues especially cancer, neurobehavioral disorders, cardiovascular problems, reduced energy levels, premature death, asthma exacerbations, headaches and dizziness, irritation of eyes, nose, mouth and throat, reduced lung functioning, respiratory symptoms, respiratory disease, disruption of endocrine and reproductive and immune systems [12].

Air pollutants cause reversible changes in respiratory symptoms and lung function, changes in airway reactivity and inflammation, structural remodeling of pulmonary airways, and impairment of pulmonary host defences, to increased respiratory morbidity and mortality. Understanding of the effects of a small group of air pollutants has advanced considerably, but the understanding is by no means complete, and the breadth of effects of all air pollutants is only partially understood [13].

The current study is showing there was a significant association between the knowledge regarding the health effects with sex, education, place of living, occupation, duration of working experience of the people among the demographic variables.

There is evidence of an association between air pollution and neurological function in both adults and children. Air pollution is important environmental and public health concerns worldwide. Identification of factors will find the susceptible groups within the population and guide to develop better health policies to protect the population [14]. The recommendation and suggestions have been provided to carry out further research works based on the limitation found in existing knowledge $[15,16]$.

\section{CONCLUSION}

The study concluded that there was the high prevalence of respiratory problems among the people residing at quarry areas. The people residing near quarry as well the workers of the quarry were very ignorant about the precautions and preventive measures of health problems especially respiratory illnesses. Most of the people were with inadequate knowledge on health effects, and there is a need to advise the people about safety and preventive measures for reducing respiratory diseases and to get the optimum health. The department of health and health workers need to provide awareness among the people to reduce the prevalence of respiratory problems. Not only that they should take the necessary action to develop the public health programs like mass education to reduce the health issues in the communities at the quarry.

\section{ACKNOWLEDGEMENT}

The authors are grateful to Dr. Mangala Gowri, Principal, SCON to permit and motivate to conduct the study.

\section{CONFLICTOF INTERESTS}

Declared none

\section{REFERENCES}

1. Urom SE, Antai AB, Osim EE. Symptoms and lung function values in Nigerian men and women exposed to dust generated from crushing of granite rocks in Calabar, Nigeria. Niger J Physiol Sci 2004;19:41-7.

2. Chhabra P, Sharma G, Kannan AT. Prevalence of respiratory disease and associated factors in an urban area of Delhi. Indian J Community Med 2008;33:229-32.

3. Rekha K, Rai S, Anandh. Effect of stretching respiratory accessory muscles in chronic obstructive pulmonary diseases. Asian J Pharm Clin Res 2016;9:104-8.

4. Isah EC, Okojie $\mathrm{OH}$, Edet E. Artisanal manual stone quarrying in a rural community of Edo State, Nigeria: implication for occupational health. J Med Biomed Res 2004;3:49-55.

5. Robert FP. The particulate air pollution controversy. Nonlinearity Biol Toxicol Med 2004;2:259-92.

6. Kim JH, Lim DH, Kim JK, Jeong SJ, Son BK. Effects of particulate matter (PM10) on the pulmonary function of middle-school children. J Korean Med Sci 2005;20:42-5.

7. Viegi G, Maio S, Pistelli F, Baldacci S, Carrozzi L. Epidemiology of chronic obstructive pulmonary disease: health effects of air pollution. Respirology 2006;11:523-32.

8. Simoni M, Baldacci S, Maio S, Cerrai S, Sarno G, Viegi G. Adverse effects of outdoor pollution in the elderly. J Thoracic Disease 2015;7:34-45.

9. Jindal SK, Aggarwal AN, Gupta D, Agarwal R, Kumar R, Kaur T, et al. Indian study on the epidemiology of asthma, respiratory symptoms and chronic bronchitis in adults (INSEARCH). Int J Tuberculosis Lung Disease 2012;16:1270-7.

10. Nwibo AN, Ugwuja EI, Nwambeke NO, Emelumdu OF, Ogbonnaya LU. Pulmonary problems among quarry workers of stone crushing industrial site at Umuoghara, Ebonyi State, Nigeria. Int J Occup Environ Med 2012;3:178-85.

11. Nartey VK, Nanor JN, Klake RK. Effects of quarry activities on some selected communities in the lower Manya Krobo District of the eastern region of Ghana. Atmos Clim Sci 2012;2:362-72.

12. Kapoor D. Impact of pharmaceutical industries on the environment, health and safety. J Crit Rev 2015;2:25-30.

13. Folinsbee LJ. Human health effects of air pollution. Environ Health Perspectives 1993;100:45-56.

14. Xu X, Ha SU, Basnet R. A review of epidemiological research on adverse neurological effects of exposure to ambient air pollution. Front Public Health 2016;4:157.

\section{How to cite this article}

- Sahbanathul Missriya MA, Subashini S. Assess the prevalence of respiratory problem and knowledge on health effects of people residing near the quarry. Int J Pharm Pharm Sci 2017;9(2):250-253. 